\title{
Linagliptin versus sitagliptin in patients with type 2 diabetes mellitus: a network meta-analysis of randomized clinical trials
}

Khosro Keshavarz ${ }^{1}$, Farhad Lotfi ${ }^{1}$, Ehsan Sanati ${ }^{2}$, Mahmood Salesi ${ }^{3}$, Amir Hashemi-Meshkini ${ }^{2}$, Mojtaba Jafari ${ }^{1}$, Mohammad M. Mojahedian ${ }^{2}$, Behzad Najafi ${ }^{4}$ and Shekoufeh Nikfar ${ }^{5^{*}}$

\begin{abstract}
Background: Diabetes is one of the most common chronic and costly diseases worldwide and type 2 diabetes is the most common type which accounts for about $90 \%$ of cases with diabetes. New medication-therapy regimens such as those containing linagliptin alone or in combination with other medications (within the category of DDP-4 inhibitors) must be evaluated in terms of efficacy and compared with other currently used drugs and then enter the medication list of the country. Hence, this study aimed to compare the clinical efficacy of the two drugs, i.e. linagliptin and sitagliptin, in patients with type 2 diabetes.
\end{abstract}

Methods: A systematic review was conducted to identify all clinical trials published by 2015 which compared the two drugs in patients with type 2 diabetes. Using keywords such as "linagliptin", "type 2 diabetes mellitus", "sitagliptin" and related combinations, we searched databases including Scopus, PubMed, and Web of Science. The quality of the selected studies was evaluated using the Jadad score. Considering primary and secondary outcomes extracted from the reviewed studies, a network meta-analysis was used to conduct a systematic comparison between the two studied drugs.

Results: This network meta-analysis included 32 studies (Linagliptin vs PLB: $n=8$, Sitagliptin vs PLB: $n=13$, Linagliptin + MET vs PLB + MET: $n=4$, and Sitagliptin + MET vs PLB + MET: $n=7$ ) and a total of 13,747 patients. The results showed no significant difference between linagliptin and sitagliptin in terms of key efficacy and safety outcomes such as HbA1c changes from baseline, body weight change from baseline, percentage of patients achieving $\mathrm{HbA} 1 \mathrm{c}<7$, and percentage of patients experiencing hypoglycemic events $(p>0.05)$. The results showed that the efficacy of the two drug regimens was the same.

Conclusions: Based on the results, there was no significant difference between the two drugs, i.e. linagliptin and sitagliptin, in terms of efficacy; in other words, the efficacy of the two drugs was the same. Therefore, the use of these two drugs depends on their availability and cost.

Keywords: Linagliptin, Type 2 diabetes mellitus, Sitagliptin, Network meta-analysis

\footnotetext{
* Correspondence: shekoufeh.nikfar@gmail.com

${ }^{5}$ Department of Pharmacoeconomics and Pharmaceutical Administration, Faculty of Pharmacy and Evidence-Based Medicine Group, Pharmaceutical Sciences Research Center, Tehran University of Medical Sciences, Tehran, Iran Full list of author information is available at the end of the article
} 


\section{Background}

The incidence and prevalence of diabetes has been rapidly increasing in the last century and morbidity and mortality from these two pandemic diseases have caused massive problems for the health of human communities $[1,2]$. Diabetes is one of the most common and a costly chronic disease worldwide, which is considered as a latent epidemic disease one of the health sector challenges around the world. Based on the statistical data published by the International diabetes Federation (IDF), currently 415 million people worldwide have diabetes and this number is predicted to reach 642 million people by 2040 . In Iran, more than 4.6 million people were affected by the disease in 2015 [3]. Recent estimates suggest that diabetes mellitus causes 59,258,034 disability adjusted life years (DALYs) in 2012 with a $89.7 \%$ increase in deaths from diabetes since 1990 to 2013 [4].

Among different types of diabetes, type 2 diabetes is the most common type which accounts for about $90 \%$ of the cases [5]. Although the prevalence of both types of diabetes, i.e. type 1 and type 2, is increasing in the world, type 2 diabetes is more prevalent and the genetic background and environmental factors can be very effective in increasing the incidence of the disease [6-8].

Diabetes has many complications which can severely affect the quality of life of the patients and impose a high economic burden on individuals and community $[9,10]$.

Among available diabetes treatments, DPP4 inhibitors are one of the new generation classes with good efficacy and safety profile [11-13]. As though in a Meta- analyze study including 62 RCT studies was indicated these kind of drugs decrease HbA1c about $76 \%$ in comparison placebo [14], In other meta-analyze including 8 RCT studies, the result was shown DPP-4 decrease the risk of heart diseases in comparison MET. It seems some drugs such as linagliptin, sitagliptin and etc. can be a suitable alternatives for patients who don't reply to MET [15].

Also, According to published clinical studies, linagliptin in this class seems to be more advantageous for patients with renal insufficiency [16]. Using evidence based approach in order to optimize resource utilization in pharmaceutical policy making has started from 2013 in Iran $[17,18]$. The aim of this study was also to compare the clinical efficiency of linagliptin and sitagliptin in patients with type 2 diabetes to provide scientific evidences to policy makers for an appropriate decision making.

\section{Methods}

\section{Data resources and search strategy}

In order to evaluate the efficacy of the two drugs, linagliptin and sitagliptin, we conducted a systematic review of the studies published by the end of 2015. Using keywords such as "linagliptin", "type 2 diabetes mellitus", "sitagliptin" and related combinations, we searched databases including Scopus, PubMed, and Web of Science (Additional file 1: Appendix).

\section{Study selection and inclusion and exclusion criteria}

Based on the inclusion criteria for this systematic review, we reviewed randomized clinical trial studies published in English that compared the clinical efficacy of linagliptin and sitagliptin. It is important to remind that these medicines had some alternatives for comparing such as placebo and metformin as shown in Tables 2 and 3 . Exclusion criteria were animal studies, non-controlled trial studies, observational studies, review studies, and economic evaluation studies.

\section{Study selection and data extraction}

PRISMA guideline was used for this systematic review, and after the initial search the duplicates were eliminated. The titles and abstracts of the remaining papers were independently evaluated by two researchers to detect and eliminate unrelated articles and those which did not meet the inclusion criteria. The results obtained by the two researchers were compared with each other and the discrepancies were resolved by referring to the articles. Then, the full-text of the selected articles was studied and the papers that met the mentioned criteria were selected.

\section{Quality assessment}

The quality of the trials was evaluated using the Jadad score system; accordingly, each study was evaluated in terms of the three indicators, including "randomized, double blinded, and withdrawal or dropout" and scored between 0 and 5 . The studies with a score more than or equal to 3 had an acceptable quality while those with a score less than 3 met the exclusion criteria. Therefore, the studies which met the intended criteria, had an acceptable quality (based on the table of Jadad score), and had the same methodology were entered into the network meta-analysis.

\section{Data analysis}

After searching and investigating the mentioned databases, we did not find any study which directly compared the two drugs; hence, we decided to find and review clinical trials which investigated DPP-4 drugs, extract the data on their efficiency, and compare the data extracted from independent studies. Therefore, in order to integrate the results of the studies, we used network meta-analysis. To carry out the analysis, we used STATA and Excel softwares.

Thus, as noted above, in this study first we used a systematic review approach to collect studies on the efficiency of the two drugs, i.e. sitagliptin and linagliptin, 
which are among DPP-4 category. Then, using network meta-analysis, we analyzed the data and compared the efficacy of the drugs. In this study, we not only evaluated the efficacy of the monotherapy using each of the drugs, but also assessed the efficacy of combination therapy using the drugs together with metformin. However, due to the lack of sufficient studies, we did not assess combination therapy with other drugs, such as sulfonylureas, insulin, and glitazones.

Moreover, in order to include a study in meta-analysis, it had to meet the following PICO criteria:

$\mathrm{P}$ (Population): Patients with type 2 diabetes.

I (Intervention): linagliptin.

C (Comparators): sitagliptin.

O (Outcomes): The desired outcomes were: "HbA1c change from baseline", "Percentage of patients achieving HbA1c < 7\%", "Percentage of patients experiencing hypoglycemic events", and "Body weight change from baseline".

To carry out this network meta-analysis, we analyzed the data using random effect approach. In this approach, first the researcher conducted a meta-analysis of the existing comparisons and combined the results via indirect meta-analysis and finally made its own comparison.

For calculating indirect effect, Bucher et al. method was used [19]. In this method the effects of lina relative to sita can be estimated indirectly as follows, using the direct estimators for the effects of PLB relative to Lina (effect $\left.t_{\text {Lina,PLB }}\right)$ and PLB relative to sita $\left(\right.$ effect $\left._{\text {Sita,PLB }}\right)$ :

$$
\text { Effect }_{\text {Lina,Sita }}=\text { effect }_{\text {Lina,PLB }}-\text { effect }_{\text {Sita,PLB }}
$$

The indirect estimator variance of Effect $t_{\text {Lina,Sita }}$ is the sum of the direct estimators variances:

$$
\text { variance }_{\text {Lina,Sita }}=\text { variance }_{\text {Lina,PLB }}+\text { variance }_{\text {Sita,PLB }}
$$

for indirect effects of Lina + MET or Sita + MET vs PLB + MET, the same formula were used.

In this study, two tables were provided for every outcome. In the first table, it was considered that the monotherapy and combination therapy studies were not similar, while in the second table the effects of monotherapy and combination therapy were considered to be similar. For each parameter in the first table, we combined the results of the meta-analysis of the existing combinations and indirectly compared linagliptin $5 \mathrm{mg}$ with sitagliptin $100 \mathrm{mg}$ and also compared LIN $5 \mathrm{mg}+$ MET with SIT $100 \mathrm{mg}+$ MET. In the second table, it was assumed that the results of comparisons between drugs with and without MET were the same; thus, we compared linagliptin $5 \mathrm{mg}$ (with and without MET) with sitagliptin $100 \mathrm{mg}$ (with and without MET). For the first two outcomes, we compared the changes from the baseline and for the second two outcomes we compared the Log of odds ratios.

\section{Results \\ Study screening, characteristics and quality of the selected studies}

After searching the electronic databases and reviewing the references of articles, a total of 3711 articles was obtained. All the obtained articles were carefully assessed to find the articles which met the intended criteria and finally a total of 32 articles which had an acceptable level of quality were selected for the metaanalysis. Table 1 presents the data on the selected papers (Fig. 1). It presents a summary of the characteristics of the selected studies, including the core of comparison, study period, and the number of patients. Moreover, using the Jadad score, we assessed the quality of all the selected studies; as the results showed, the all the selected studies which underwent quality assessment obtained a score equal to or more than three.

\section{Outcomes}

Network meta-analysis was used to compare different groups in terms of HbA1c changes from baseline, body weight change from baseline, percentage of patients achieving HbA1c $<7$, and percentage of patients experiencing hypoglycemic events. Figure 2 presents a schematic of the various comparisons between the groups. Figures $2 \mathrm{a}-\mathrm{d}$, respectively, show the number of studies which presented outcomes for HbAlc changes from baseline, body weight change from baseline, percentage of patients achieving $\mathrm{HbA} 1 \mathrm{c}<7$, and percentage of patients experiencing hypoglycemic events; these figures compare linagliptin and sitagliptin groups with the placebo group and compare LIN $5 \mathrm{mg}+$ MET and SIT $100 \mathrm{mg}+$ MET groups with PLB + MET group. The maximum total number of studies was 32; HbA1c changes from baseline was the outcome with the largest number of studies (32 studies) while body weight change from baseline was the outcome with the least number of studies (18 studies).

\section{HbA1c change from baseline}

Based on the results of the meta-analysis presented in Table 2, the two groups of linagliptin and sitagliptin were significantly different from the placebo group in terms of HbA1c changes from baseline, as these two drugs, respectively, reduced $\mathrm{HbA1c}$ by 0.644 and 0.284 units as compared with the placebo (comparisons 1 and 2). In addition, there was no significant difference between the LIN $5 \mathrm{mg}+$ MET group and PLB + MET group in terms of $\mathrm{HbAlc}$ changes from baseline (comparison 3). However, it showed a significant 
Table 1 Summarized characteristics of the selected studies in the network meta-analysis

\begin{tabular}{|c|c|c|c|c|c|c|}
\hline Study identifier References & Treatment 1 & Treatment 2 & $\mathrm{~N}$ & Weeks & Age Mean (s.d.) & Sex (males) N (\%) \\
\hline \multicolumn{7}{|l|}{ Linagliptin Mono. (8 RCTs) } \\
\hline Del Prato et al. (2011) [31] & LIN 5 mg & PLB & 503 & 24 & $55.7(10.2)$ & $243(48.3)$ \\
\hline Haak et al. (2012) [32] & LIN 5 mg & PLB & 214 & 24 & $55.95(10.9)$ & $116(54.2)$ \\
\hline Kawamori (2012) [33] & LIN 5 mg & PLB & 239 & 12 & $60.0(9.1)$ & $168(70.2)$ \\
\hline Barnett et al. (2012) [34] & LIN 5 mg & PLB & 227 & 18 & $56.5(10.3)$ & $88(38.7)$ \\
\hline Lajara (2014) [35] & LIN 5 mg & PLB & 202 & 24 & $69.1(10.0)$ & $122(60.4)$ \\
\hline Chen et al. (2015) [36] & LIN 5 mg & PLB & 299 & 24 & $54.3(9.7)$ & $175(58.5)$ \\
\hline Taskinen (2011) [37] & LIN 5 mg & PLB & 700 & 24 & $56.5(10.3)$ & $379(54.1)$ \\
\hline Inzucchi (2015) [38] & LIN 5 mg & PLB & 247 & 24 & $74.3(3.9)$ & $126(51.0)$ \\
\hline \multicolumn{7}{|l|}{ Sitagliptin Mono. (13 RCTs) } \\
\hline Barzilai et al. (2011) [39] & SIT 100 mg & PLB & 206 & 24 & $72.0(6.0)$ & $97(47.1)$ \\
\hline Nonaka et al. (2008) [40] & SIT $100 \mathrm{mg}$ & PLB & 151 & 12 & $55.3(8.3)$ & $95(62.9)$ \\
\hline Aschner et al. (2006) [41] & SIT 100 mg & PLB & 491 & 24 & - & - \\
\hline Goldstein et al. (2007) [42] & SIT $100 \mathrm{mg}$ & PLB & 355 & 24 & - & - \\
\hline Hanefeld et al. (2007) [43] & SIT $100 \mathrm{mg}$ & PLB & 221 & 12 & $56.0(8.5)$ & $131(59.2)$ \\
\hline Scott (2008) [44] & SIT $100 \mathrm{mg}$ & PLB & 186 & 18 & $55.2(9.5)$ & $106(57.9)$ \\
\hline Raz (2008) [45] & SIT $100 \mathrm{mg}$ & PLB & 190 & 30 & $54.8(9.5)$ & $88(46.3)$ \\
\hline Charbonnel (2006) [46] & SIT 100 mg & PLB & 701 & 24 & - & - \\
\hline Pe'rez-Monteverde et al. (2011) [47] & SIT 100 mg & PLB & 492 & 12 & - & - \\
\hline Russell-Jones et al. (2012) [48] & SIT 100 mg & PLB & 409 & 26 & 54 & 59 \\
\hline Nauck 2007 [49] & SIT 100 mg & PLB & 1172 & 52 & $56.7(9.5)$ & $694(59.2)$ \\
\hline Arechavaleta 2011 [50] & SIT 100 mg & PLB & 1035 & 30 & $56.2(9.9)$ & $563(54.4)$ \\
\hline Bergenstal (2010) [51] & SIT 100 mg & PLB & 331 & 26 & $52.5(10.5)$ & $165(49.8)$ \\
\hline \multicolumn{7}{|l|}{ Linagliptin Com. (4 RCTs) } \\
\hline Forst et al. (2010) [52] & LIN 5 mg + MET & PLB+ MET & 137 & 12 & $59.8(8.9)$ & $81(59.1)$ \\
\hline Gallwitz et al. (2012) [53] & LIN 5 mg + MET & PLB+ MET & 1551 & 104 & $59.8(9.4)$ & $933(60.1)$ \\
\hline Taskinen et al. (2011) [37] & LIN 5 mg + MET & PLB+ MET & 700 & 24 & $56.5(10.3)$ & $379(54.1)$ \\
\hline Ross et al. (2012) [54] & LIN 5 mg + MET & PLB+ MET & 268 & 12 & $59.1(10.6)$ & $142(52.9)$ \\
\hline \multicolumn{7}{|l|}{ Sitagliptin Com. (7 RCTs) } \\
\hline Aaboe et al. (2010) [55] & SIT $100 \mathrm{mg}+\mathrm{MET}$ & PLB+ MET & 24 & 12 & 59.8 & $17(70.8)$ \\
\hline Arechavaleta et al. (2011) [50] & SIT 100 mg + MET & PLB+ MET & 1035 & 30 & $56.2(9.9)$ & $563(54.4)$ \\
\hline Charbonnel et al. (2006) [46] & SIT 100 mg + MET & PLB+ MET & 678 & 24 & - & - \\
\hline Derosa et al. (2012) [56] & SIT $100 \mathrm{mg}+\mathrm{MET}$ & PLB+ MET & 178 & 52 & $55.4(8.4)$ & $86(48.3)$ \\
\hline Raz et al. (2008) [45] & SIT 100 mg + MET & PLB+ MET & 190 & 30 & $54.8(9.5)$ & $88(46.3)$ \\
\hline Scott et al. (2008) [44] & SIT 100 mg + MET & PLB+ MET & 186 & 18 & $55.2(9.5)$ & $106(56.9)$ \\
\hline Hermansen et al. (2007) [57] & SIT 100 mg + MET & PLB+ MET & 229 & 24 & $57.1(8.8)$ & $120(52.4)$ \\
\hline
\end{tabular}

difference in SIT $100 \mathrm{mg}+$ MET group, as compared with $\mathrm{PLB}+\mathrm{MET}$ group, so that the drug reduced HbA1c by 0.555 units in PLB + MET group (comparison 4). Then, the results of the reported meta-analyses were combined and an indirect comparison showed a significant difference in HbA1c from baseline in linagliptin group, as compared with the sitagliptin group; in other words, linagliptin decreased HbA1c by 0.359 units, as compared with sitagliptin (comparison 5). However, the changes in LIN $5 \mathrm{mg}+\mathrm{MET}$ group, as compared with SIT $100 \mathrm{mg}+$ MET group, did not show a significant difference (comparison 6).

\section{Body weight change from baseline}

Table 2 shows no significant difference between the linagliptin and placebo groups (comparison 1) and between sitagliptin groups and placebo group (comparison 2 ) in terms of body weight changes from baseline. However, it had a significant difference in LIN $5 \mathrm{mg}+$ MET 


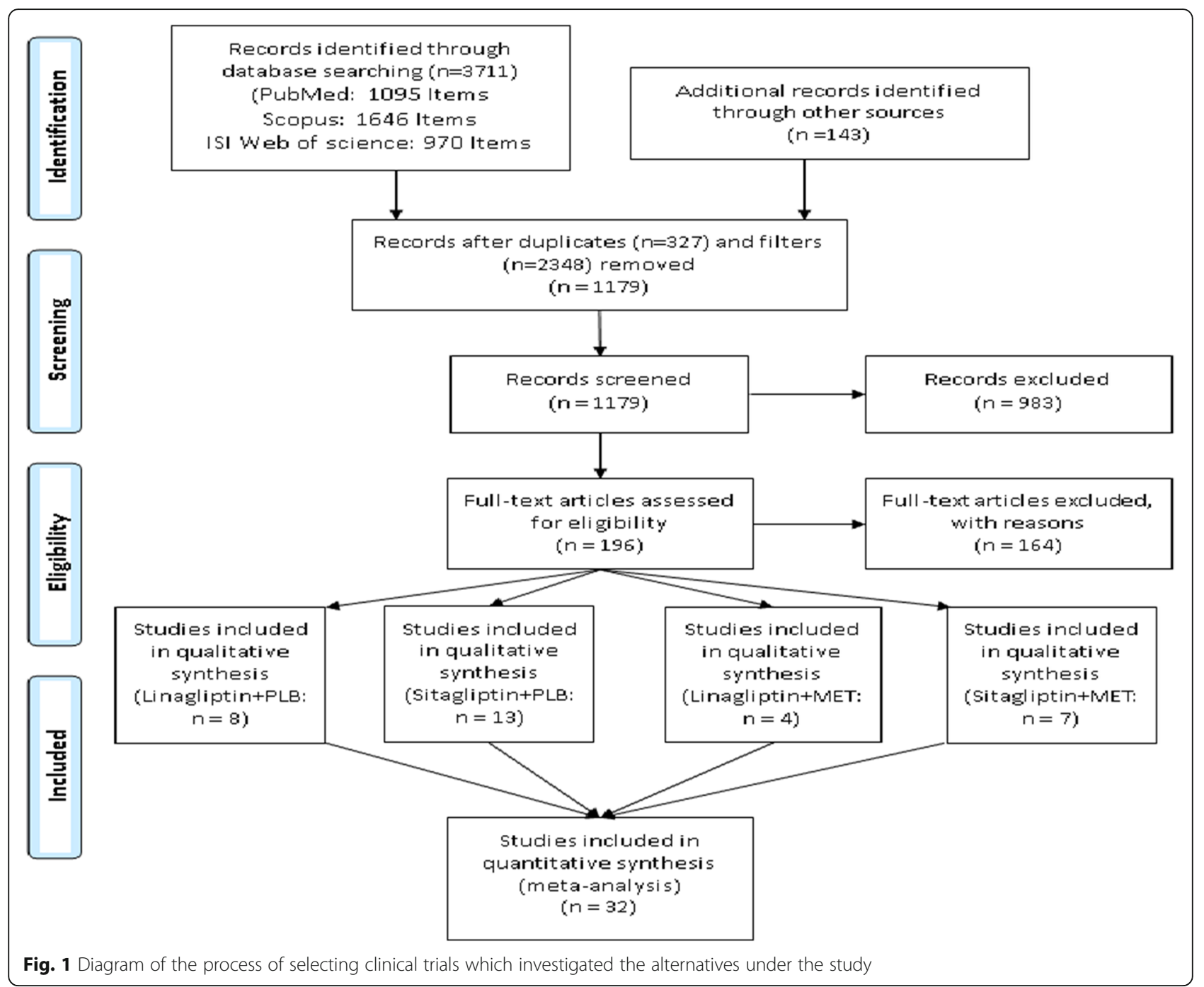

group, as compared with the PLB + MET group, so that the drug reduced the body weight by 2.489 units, as compared with the PLB + MET group (comparison 3). On the other hand, there was no significant difference in the SIT $100 \mathrm{mg}+$ MET group, as compared with the PLB + MET group (comparison 4).

Then, the results of reported meta-analyses were combined and an indirect comparison showed no significant difference between linagliptin and sitagliptin groups in terms of body weight changes from baseline (comparison 5). However, it showed a significant difference in the LIN $5 \mathrm{mg}+$ MET group as compared with the SIT $100 \mathrm{mg}+$ MET groups, so that LIN $5 \mathrm{mg}+$ MET decreased body weight by 2.288 units, as compared with SIT $100 \mathrm{mg}+$ MET (comparison 6).

\section{Percentage of patients achieving HbA1c $<7$}

As shown in Table 2, the percentage of patients achieving HbA1c $<7$ significantly increased in the linagliptin group, as compared with the placebo group; the odds ratio of HbA1c $<7$ in this group was 2.04 times more than that in the placebo group (comparison 1). However, it did not show a significant difference in the sitagliptin group, as compared with the placebo group (comparison 2). In addition, comparing the percentage of $\mathrm{HbA1c}<7$ showed that there was no significant difference between the LIN $5 \mathrm{mg}+$ MET group and PLB + MET group (comparison 3) and between the SIT $100 \mathrm{mg}+$ MET group and PLB + MET group (comparison 4). Then, the results of reported metaanalyses were combined and an indirect comparison of the percentage of HbAlc $<7$ showed no significant difference between the linagliptin group and sitagliptin group (comparison 5) and between the LIN $5 \mathrm{mg}+$ MET group and SIT $100 \mathrm{mg}+$ MET group (comparison 6).

Percentage of patients experiencing hypoglycemic events As shown in Table 2, the percentage of patients experiencing hypoglycemic events significantly decreased in 


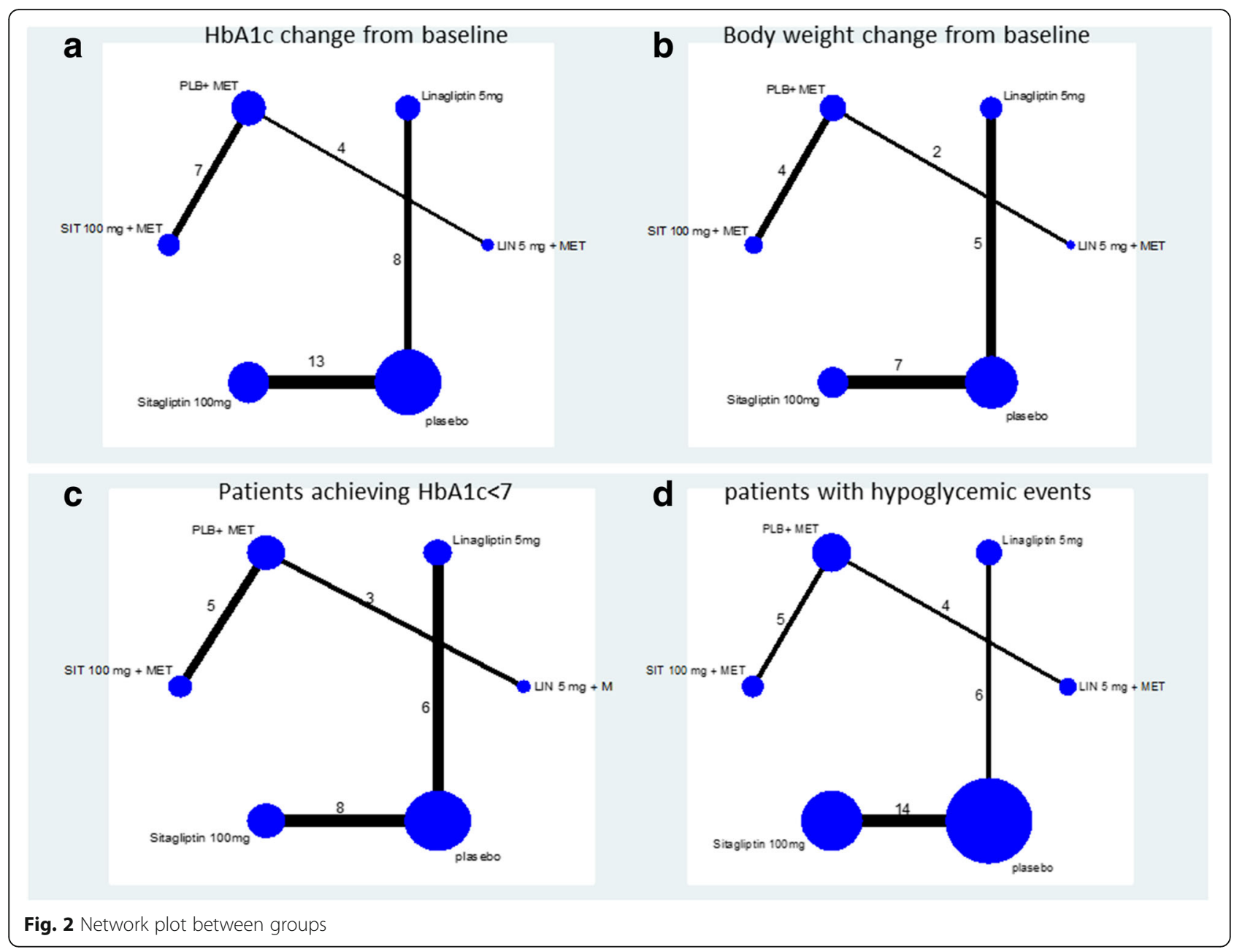

the linagliptin and sitagliptin groups, as compared with the placebo group; the odds ratio of hypoglycemic events in the two groups was 0.53 and 0.44 , respectively, as compared with the placebo group (comparisons 1 and 2). Moreover, the percentage of hypoglycemic events significantly decreased in the LIN $5 \mathrm{mg}+$ MET group, as compared with the PLB + MET group; the odds ratio of hypoglycemic events in the LIN $5 \mathrm{mg}+$ MET group was $\mathrm{OR}=\exp \cdot(-1.853)=0.15$ times more than that in the PLB + MET group (comparison 3). However, there was no significant difference between the SIT $100 \mathrm{mg}+$ MET group and PLB + MET group (comparison 4). Then, the results of reported metaanalyses were combined and an indirect comparison of hypoglycemic events showed no significant difference between the linagliptin group and sitagliptin group (comparison 5). However, it significantly decreased in the LIN $5 \mathrm{mg}+$ MET group, as compared with the SIT $100 \mathrm{mg}+$ MET group; the odds ratio of hypoglycemic events in the LIN $5 \mathrm{mg}+$ MET group was $\mathrm{OR}=\exp \cdot(-1.426)=0.24$ times more than that in the SIT $100 \mathrm{mg}+$ MET group (comparison 6).
As shown in Table 3, considering the similarities between comparisons 1 and 3 and between comparisons 2 and 4, there was a significant difference in HbAlc changes from baseline in the linagliptin and sitagliptin groups (with and without MET), as compared with the placebo group; the mentioned drugs, respectively, reduced $\mathrm{HbA} 1 \mathrm{c}$ by 0.495 and 0.375 units, as compared with the placebo group (comparisons 7 and 8). However, finally, there was no significant difference between the linagliptin group (with and without MET), as compared with the sitagliptin group (with and without MET) (comparison 9).

Comparing the groups in terms of body weight changes from baseline showed that there was no significant difference between the linagliptin and sitagliptin groups (with and without MET), as compared with the placebo group (with and without MET) (comparisons 7 and 8). In addition, finally, there was no significant difference between the linagliptin group (with and without MET), as compared with the sitagliptin group (with and without MET) in terms of body weight changes from baseline (comparison 9). 


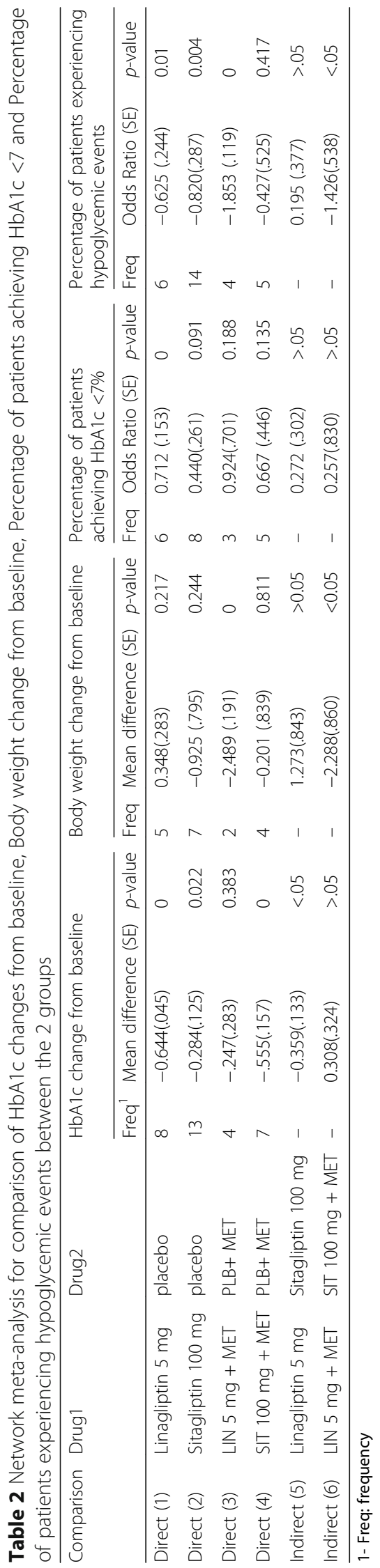


Table 3 Network meta-analysis for comparison HbA1c changes from baseline, Body weight change from baseline, Percentage of patients achieving $\mathrm{HbA} 1 \mathrm{c}<7$ and Percentage of patients experiencing hypoglycemic events between 2 groups (If in Table 2 pairs (1 similar 3) \& (2 similar 4))

\begin{tabular}{|c|c|c|c|c|c|c|c|c|c|c|c|c|c|c|}
\hline \multirow[t]{2}{*}{ Comparison } & \multirow[t]{2}{*}{ Drug1 } & \multirow[t]{2}{*}{ Drug2 } & \multicolumn{3}{|c|}{ HbA1c change from baseline } & \multicolumn{3}{|c|}{$\begin{array}{l}\text { Body weight change } \\
\text { from baseline }\end{array}$} & \multicolumn{3}{|c|}{$\begin{array}{l}\text { Percentage of patients } \\
\text { achieving } \mathrm{HbA} 1 \mathrm{c}<7 \%\end{array}$} & \multicolumn{3}{|c|}{$\begin{array}{l}\text { Percentage of patients } \\
\text { experiencing hypoglycemic } \\
\text { events }\end{array}$} \\
\hline & & & Freq & Mean difference (SE) & $p$-value & Freq & Mean difference (SE) & $p$-value & Freq & Ln(OR) (SE) & $p$-value & Freq & $\operatorname{Ln}(\mathrm{OR})(\mathrm{SE})$ & $p$-value \\
\hline Direct (7) & $\begin{array}{l}\text { Linagliptin } \\
5 \mathrm{mg}\end{array}$ & placebo & 12 & $-.495(.119)$ & 0 & 7 & $-0.211(.701)$ & 0.764 & 9 & $0.711(.257)$ & 0.006 & 10 & $-1.250(.271)$ & 0 \\
\hline Direct (8) & $\begin{array}{l}\text { Sitagliptin } \\
100 \mathrm{mg}\end{array}$ & placebo & 20 & $-.375(.072)$ & 0 & 11 & $-0.664(.553)$ & 0.229 & 13 & $0.514(.209)$ & 0.014 & 19 & $-0.753(.228)$ & 0.001 \\
\hline Indirect (9) & $\begin{array}{l}\text { Linagliptin } \\
5 \mathrm{mg}\end{array}$ & $\begin{array}{l}\text { Sitagliptin } \\
100 \mathrm{mg}\end{array}$ & - & $-0.12(.139)$ & $>.05$ & - & $0.454(.893)$ & $>0.05$ & - & $0.197(.332)$ & $>.05$ & 4 & $-0.497(.354)$ & $>0.05$ \\
\hline
\end{tabular}

Comparing the groups in terms of the percentage of HbA1c $<7$ revealed that there was a significant difference between the linagliptin and sitagliptin groups (with and without MET), as compared with the placebo group (with and without MET) as the odds ratio of HbA1c in the linagliptin and sitagliptin groups, respectively, was 2.03 and 1.67, as compared with the placebo group (comparisons 7 and 8). However, finally, there was no significant difference between the linagliptin group (with and without MET), as compared with the sitagliptin group (with and without MET) (comparison 9).

Comparing the groups in terms of hypoglycemic events showed that there was a significant difference between the linagliptin and sitagliptin groups (with and without MET), as compared with the placebo group (with and without MET) as the odds ratio of hypoglycemic events in the linagliptin and sitagliptin groups, respectively, was 0.28 and 0.47 , as compared with the placebo group (comparisons 7 and 8). However, there was no significant difference between the linagliptin group (with and without MET), as compared with the sitagliptin group (with and without MET) (comparison 9).

\section{Discussion}

Using meta-analyses approach, we performed a directcomparison between the drugs and placebo that the results were different. The results of the meta-analysis showed a significant difference in HbA1c changes from baseline in the linagliptin group and sitagliptin group (with and without MET), as compared with the placebo group, because HbA1c was reduced by these drugs, as compared with the placebo. It is in the same line with the results of the study of Gross JL et al. [20] However, there was no significant difference in the LIN $5 \mathrm{mg}+$ MET group, as compared with the PLB + MET group.

Considering body weight changes from baseline revealed that there was no significant difference between the linagliptin and placebo groups and between the sitagliptin groups (with and without MET) and placebo group. However, it showed a significant difference in the LIN $5 \mathrm{mg}+$ MET group, as compared with the PLB + MET group, so that the drug reduced body weight, compared with the PLB + MET group.

As to the percentage of patients achieving HbA1c $<7$, it significantly increased in the linagliptin group, as compared with the placebo group; the odds ratio of HbA1c $<7$ in this group was two times more than that of the placebo group. However, there was no significant difference in the LIN $5 \mathrm{mg}+$ MET and sitagliptin groups (with and without MET), as compared with the placebo group. Moreover, as to the percentage of hypoglycemic events, there was a significant difference in the linagliptin (with and without MET) and sitagliptin groups, as compared with the placebo group. The odds ratio of hypoglycemic events in the two groups was less than that in the placebo group. Nevertheless, there was no significant difference in the SIT $100 \mathrm{mg}+$ MET group, as compared with PLB + MET group.

The results of network meta-analysis showed no significant difference in HbA1c changes from baseline, body weight changes from baseline, percentage of HbA1c $<7$, and percentage of hypoglycemic events in the linagliptin group (with and without MET), as compared with the sitagliptin group (with and without MET); thus, the efficiency of the two drugs are identical. Therefore, the results of this study are consistent with those of the studies conducted in other countries [20-22].

As noted in the results, in certain cases linagliptin has a relative advantage in pharmacokinetic superiority over sitagliptin; thus, it can be considered as a suitable alternative. Non-renal clearance is one of the pharmacokinetic features of linagliptin which makes it different from other gliptins available on the market. Therefore, its use in patients with renal insufficiency is safe and does not have any restriction [16]. Therefore, this drug is more advantageous, as compared with other drugs in this category, and is considered to be the treatment of choice in patients with renal insufficiency because kidney dysfunction is quite common in diabetic patients [23-26]. 
Although the efficacy of linagliptin and sitagliptin is the same, because the use of linagliptin has no restrictions in patients with renal dysfunction, and this drug is a better alternative for patients with renal dysfunction, it is necessary to make it accessible in Iran pharmaceutical market along with sitagliptin so that the physicians have an opportunity to prescribe thesedrugs for patients with different background diseases.

The results of meta-analysis can be different from those of indirect comparisons; however, we should be more cautious when interpreting the results of indirect comparisons. Systematic reviews and evaluation of the quality of clinical trials can help reduce the errors in the results of network meta-analysis but when there is a difference between the results of direct-comparison meta-analysis and indirect meta-analysis, it is necessary to re-examine the validity and generalizability of clinical trials to find the reason for the error. On the other hand, recent experimental results indicate the match between these two types of comparisons [27]. When using studies with a low quality, the results of indirect-comparison meta-analysis may be incomplete [28, 29]; on the other hand, it might be considered incomplete due to inherent differences caused via choosing the right plan, or due to limitations in comparing all the items one by one [30]. However, in this study, all the studies were examined in detail by expert people and they underwent quality assessment. At the end, this study compared linagliptin and sitagliptin drugs in terms of main efficacy and safety outcomes mentioned above. The results of this study showed no significant difference between linagliptin and sitagliptin in terms of clinical efficiency. Therefore, given their similar level of efficacy, the use of these two drugs depends on their availability and cost. According to this fact that efficacy of Linagliptin and sitagliptin is not statistically different in terms of main outcomes, any recommendation for use of each of them could be only based on cost and renal functionality of patients. For patients with renal impairments who cannot use sitagliptin and are preferred to use DPP4 inhibitors, linagliptin is a good choice. But for other patients, an economic study should be performed on the results of this study to consider economic perspective in decision making.

\section{Conclusion}

The results showed no significant difference between linagliptin and sitagliptin in terms of clinical efficacy and they had the same effect. However, as there is no restriction on the use of linagliptin in patients with renal dysfunction, it might be considered as a treatment of choice. Hence, it is recommended to include this drug, along with sitagliptin, in the list of pharmaceuticals in Iran.

\section{Additional file}

Additional file 1: Appendix. Search strategies. (DOC $215 \mathrm{~kb}$ )

\section{Abbreviations}

DALYs: Disability adjusted life years; DPP- 4: Dipeptidyl peptidase-4 inhibitors; IDF: International diabetes Federation; LIN: Linagliptin; MET: Metformin; OR: Odds Ratio; PICO: Population; Intervention; Comparators; Outcomes; PLB: Placebo; SIT: Sitagliptin

\section{Acknowledgements \\ The authors would like to thank Shafayab Gostar Company for cooperation and providing data; Shiraz University of Medical Sciences, Shiraz, Iran and also Center for Development of Clinical Research of Nemazee Hospital and Dr. Nasrin Shokrpour for editorial assistance.}

\section{Funding}

This paper was supported by Shafayab Gostar Company, Tehran, Iran.

\section{Availability of data and materials}

Datasets analyzed during the current study available from the corresponding author on reasonable request.

\section{Authors' contributions}

KHK: Study concept and design, participated in literature bibliography, Acquisition of data, Analysis and interpretation of data, Drafting of the manuscript, Critical revision of the manuscript for important intellectual content. ES: Drafting of the manuscript, Acquisition of data. MS: Drafting of the manuscript and Statistical analysis. FL: Drafting of the manuscript, revised the paper critically for important intellectual content. AHM and BN: participate in design of study and final revision of the manuscript. MJ and MM: participated in literature bibliography and collecting clinical data. SHN: participate in design of study and supervised whole study and revised the paper critically for important intellectual content. All authors read and approved the final manuscript.

\section{Ethics approval and consent to participate}

Not applicable.

\section{Consent for publication}

Not applicable.

\section{Competing interests}

The authors declare that they have no competing interests.

\section{Publisher's Note}

Springer Nature remains neutral with regard to jurisdictional claims in published maps and institutional affiliations.

\section{Author details}

${ }^{1}$ Health Human Resources Research Center, Department of Health Economics, School of Management and Information Sciences, Shiraz University of Medical Sciences, Shiraz, IR, Iran. ${ }^{2}$ Department of Pharmacoeconomics and Pharmaceutical Administration, Faculty of Pharmacy, Tehran University of Medical Sciences, Tehran, IR, Iran.

${ }^{3}$ Atherosclerosis Research center, Baqiyatallah University of Medical Sciences, Tehran, IR, Iran. ${ }^{4}$ Iranian center of Excellence in health management, Department of health services management, School of management and medical informatics, Tabriz University of medical sciences, Tabriz, Iran. ${ }^{5}$ Department of Pharmacoeconomics and Pharmaceutical Administration, Faculty of Pharmacy and Evidence-Based Medicine Group, Pharmaceutical Sciences Research Center, Tehran University of Medical Sciences, Tehran, Iran.

Received: 18 July 2017 Accepted: 2 October 2017

Published online: 25 October 2017

\section{References}

1. American Diabetes A. Economic costs of diabetes in the U.S. in 2012. Diabetes Care. 2013;36(4):1033-46. 
2. Wong J, Constantino M, Yue DK. Morbidity and mortality in young-onset type 2 diabetes in comparison to type 1 diabetes: where are we now? Curr Diab Rep. 2015;15(1):566

3. International Diabetes Federation: IDF Diabetes. 7th ed. 2015. Available at: http://www.diabetesatlas.org/component/attachments/?task= download\&id=116.

4. Najafi B, Farzadfar F, Ghaderi H, Hadian M. Cost effectiveness of type 2 diabetes screening: a systematic review. Med J Islamic Repub Iran. 2016;30:326.

5. Boyle JP, Honeycutt AA, Narayan KM, Hoerger TJ, Geiss LS, Chen H, et al. Projection of diabetes burden through 2050. Diabetes Care. 2001;24(11):1936.

6. Bener A, Al-Hamaq AO. Predictions burden of diabetes and economics cost: contributing risk factors of changing disease prevalence and its pandemic impact to Qatar. Exp Clin Endocrinol Diabetes. 2016;124(8):504-11.

7. Marshall JA, Hamman RF, Baxter J, Mayer EJ, Fulton DL, Orleans M, et al. Ethnic differences in risk factors associated with the prevalence of noninsulin-dependent diabetes mellitus. The San Luis Valley diabetes study. Am J Epidemiol. 1993;137(7):706-18.

8. Korner J, Aronne LJ. The emerging science of body weight regulation and its impact on obesity treatment. J Clin Invest. 2003;111(5):565-70.

9. Zhong Y, Lin PJ, Cohen JT, Winn AN, Neumann PJ. Cost-utility analyses in diabetes: a systematic review and implications from real-world evidence. Value Health. 2015;18(2):308-14.

10. Ulrich S, Holle R, Wacker M, Stark R, Icks A, Thorand B, et al. Cost burden of type 2 diabetes in Germany: results from the population-based KORA studies. BMJ Open. 2016;6(11):e012527.

11. Scheen AJ. Pharmacokinetics of dipeptidylpeptidase-4 inhibitors. Diabetes Obes Metab. 2010;12:648-58.

12. Romero M, Marrugo R, Sanchez O, Lopez S, Alvis N. Cost-effectiveness analysis of using hypoglycemic agents (Linagliptin, Saxagliptin, Sitagliptin, Vildagliptin, Glimepiride and Glibenclamide) with Metformin in diabetes in Colombia. Value Health, 16. (3):A163.

13. Scheen AJ, Charpentier G, Ostgren CJ, et al. Efficacy and safety of saxagliptin in combination with metformin compared with sitagliptin in combination with metformin in adult patients with type 2 diabetes mellitus. Diabetes Metab Res Rev. 2010;26:540-9.

14. Park H, Park C, Kim Y, Rascati KL. Efficacy and safety of dipeptidyl peptidase4 inhibitors in type 2 diabetes: meta-analysis. Ann Pharmacother. 2012; 46(11):1453-69.

15. Wu D, Li L, Liu C. Efficacy and safety of dipeptidyl peptidase-4 inhibitors and metformin as initial combination therapy and as monotherapy in patients with type 2 diabetes mellitus: a meta-analysis. Diabetes Obes Metab. 2014;16(1):30-7.

16. McKeage K. Linagliptin: an update of its use in patients with type 2 diabetes mellitus. Drugs. 2014;74(16):1927-46.

17. Kavosi Z, Khorrami MS, Keshavarz K, Jafari A, Meshkini AH, Safaei HR, Nikfar S. Is Taurolidine-citrate an effective and cost-effective hemodialysis catheter lock solution? A systematic review and cost-effectiveness analysis. Med J Islamic Repub Iran. 2016;30:347.

18. Keshavarz K, Hashemi-Meshkini A, Gharibnaseri Z, Nikfar S, Kebriaeezadeh A, Abdollahi M. A systematic cost-effectiveness analysis of pregabalin in the management of fibromyalgia: an Iranian experience. Archives Med Sci. 2013;9(6):961.

19. Bucher HC, Guyatt GH, Griffith LE, Walter SD. The results of direct and indirect treatment comparisons in meta-analysis of randomized controlled trials. J Clin Epidemiol. 1997;50:683-91.

20. Gross JL, Rogers J, Polhamus D, Gillespie W, Friedrich C, Gong Y, et al. A novel model-based meta-analysis to indirectly estimate the comparative efficacy of two medications: an example using DPP-4 inhibitors, sitagliptin and linagliptin, in treatment of type 2 diabetes mellitus. BMJ Open. 2013;3(3):e001844

21. Craddy P, Palin HJ, Johnson Kl. Comparative effectiveness of Dipeptidylpeptidase-4 inhibitors in type 2 diabetes: a systematic review and mixed treatment comparison. Diabetes Ther 2014;5(1):1-41. PubMed PMID: 24664619.

22. Kamatani N, Katoh T, Sawai Y, Kanayama H, Katada N, Itoh M. Comparison between the clinical efficacy of linagliptin and sitagliptin. J Diabetes. 2013;4(4):51-4.

23. McGill JB. Linagliptin for type 2 diabetes mellitus: a review of the pivotal clinical trials. Ther Adv Endocrinol Metab. 2012;3(4):113-24.
24. Gupta V, Kalra S. Choosing a Gliptin. Indian J Endocrinol Metab. 2011;15(4):298-308. PubMed PMID: 22029001

25. Deacon C. Dipeptidyl peptidase-4 inhibitors in the treatment of type 2 diabetes: a comparative review. Diabetes Obes Metab. 2011;13(1):7-18.

26. Fuchs H, Tillement JP, Urien S, Greischel A, Roth W. Concentrationdependent plasma protein binding of the novel dipeptidyl peptidase 4 inhibitor BI 1356 due to saturable binding to its target in plasma of mice, rats and humans. J Pharm Pharmacol. 2009;61(1):55-62

27. Bucher HC, Guyatt GH, Griffith LE, Walter SD. The results of direct and indirect treatment comparisons in meta-analysis of randomized controlled trials. J Clin Epidemiol. 1997;50(6):683-91.

28. Song F, Glenny AM, Altman DG. Indirect comparison in evaluating relative efficacy illustrated by antimicrobial prophylaxis in colorectal surgery. Control Clin Trials. 2000;21(5):488-97.

29. Song F, Xiong T, Parekh-Bhurke S, Loke YK, Sutton AJ, Eastwood AJ, et al. Inconsistency between direct and indirect comparisons of competing interventions: meta-epidemiological study. BMJ. 2011;343:d4909.

30. Glenny AM, Altman DG, Song F, Sakarovitch C, Deeks JJ, D'Amico R, et al. Indirect comparisons of competing interventions. Health Technol Assess. 2005;9(26):1-134. iii-iv

31. Del Prato S, Barnett AH, Huisman $H$, Neubacher D, Woerle HJ, Dugi KA. Effect of linagliptin monotherapy on glycaemic control and markers of bcell function in patients with inadequately controlled type 2 diabetes: a randomized controlled trial. Diabetes Obes Metab. 2011;13(3):258-67.

32. Haak T, Meinicke $T$, Jones $R$, Weber $S$, Von Eynatten M, Woerle HJ. Initial combination of linagliptin and metformin improves glycaemic control in type 2 diabetes: a randomized, double-blind, placebocontrolled study. Diabetes Obes Metab. 2012;14(6):565-74.

33. Kawamori $\mathrm{R}$, Inagaki $\mathrm{N}$, Araki $\mathrm{E}$, et al. Linagliptin monotherapy provides superior glycaemic control versus placebo or voglibose with comparable safety in Japanese patients with type 2 diabetes: a randomized, placebo and active comparatorcontrolled, double-blind study. Diabetes Obes Metab. 2012;14(4):348-57

34. Barnett $\mathrm{AH}$, Patel $\mathrm{S}$, Harper $\mathrm{R}$, et al. Linagliptin monotherapy in type 2 diabetes patients for whom metformin is inappropriate: an 18-week randomized, double-blind, placebo-controlled phase III trial with a 34-week active-controlled extension. Diabetes Obes Metab. 2012;14:1145-54.

35. Lajara R, Aguilar R, Hehnke U, Woerle HJ, Eynatten M. Efficacy and safety of Linagliptin in subjects with long standing type 2 diabetes mellitus ( $>10$ Years): evidence from pooled data of randomized, doubleblind, placebocontrolled, phase III trials. Clinical Therapeutics. 2014;36(11):1595-605.

36. Chen Y, Ning G, Wang C, Gong Y, Patel S, Zhang C, Izumoto T, Woerle HJ, Wang W. Efficacy and safety of linagliptin monotherapy in Asian patients with inadequately controlled type 2 diabetes mellitus: a multinational, 24-week, randomized, clinical trial. J Diabetes Investig. 2015;6:692-8.

37. Taskinen MR, Rosenstock J, Tamminen I, et al. Safety and efficacy of linagliptin as add-on therapy to metformin in patients with type 2 diabetes: a randomized, double-blind, placebo-controlled study. Diabetes Obes Metab. 2011:13(1):65-74.

38. Inzucchi SE, Nauck MA, Hehnke U, Woerle HJ, Eynatten M, Henry RR. Improved glucose control with reduced hypoglycaemic risk when linagliptin is added to basal insulin in elderly patients with type 2 diabetes. Diab. Obes Metab. 2015;17:868-77.

39. Barzilai N, Guo H, Mahoney EM, et al. Efficacy and tolerability of sitagliptin monotherapy in elderly patients with type 2 diabetes: a randomized, double-blind, placebo-controlled trial. Curr Med Res Opin. 2011;27(5): 1049-58.

40. Nonaka K, Kakikawa T, Sato A, et al. Efficacy and safety of sitagliptin monotherapy in Japanese patients with type 2 diabetes. Diabetes Res Clin Pract. 2008;79(2):291-8.

41. Aschner P, Kipnes MS, Lunceford JK, Sanchez M, Mickel C, Williams-Herman DE. Effect of the dipeptidyl peptidase-4 inhibitor sitagliptin as monotherapy on glycemic control in patients with type 2 diabetes. Diabetes Care. 2006; 29(12):2632-7.

42. Goldstein BJ, Feinglos MN, Lunceford JK, Johnson J, Williams-Herman DE. Effect of initial combination therapy with sitagliptin, a dipeptidyl peptidase4 inhibitor, and metformin on glycemic control in patients with type 2 diabetes. Diabetes Care. 2007;30(8):1979-87.

43. Hanefeld M, Herman GA, Wu M, Mickel C, Sanchez M, Stein PP. Once-daily sitagliptin, a dipeptidyl peptidase-4 inhibitor, for the treatment of patients with type 2 diabetes. Curr Med Res Opin. 2007;23(6):1329-39. 
44. Scott R, Loeys T, Davies MJ, Engel SS. Efficacy and safety of sitagliptin when added to ongoing metformin therapy in patients with type 2 diabetes. Diabetes Obes Metab. 2008;10(10):959-69.

45. Raz I, Chen Y, Wu M, et al. Efficacy and safety of sitagliptin added to ongoing metformin therapy in patients with type 2 diabetes. Curr Med Res Opin. 2008;24(2):537-50.

46. Charbonnel B, Karasik A, Liu J, Wu M, Meininger G. Efficacy and safety of the dipeptidyl peptidase-4 inhibitor sitagliptin added to ongoing metformin therapy in patients with type 2 diabetes inadequately controlled with metformin alone. Diabetes Care. 2006;29(12):2638-43.

47. Pérez-Monteverde A, Seck T, Xu L, et al. Efficacy and safety of sitagliptin and the fixed-dose combination of sitagliptin and metformin vs. pioglitazone in drug-naï ve patients with type 2 diabetes. Int J Clin Pract. 2011;65(9):930-8.

48. Russell-Jones D, Cuddihy RM, Hanefeld M, et al. Efficacy and safety of exenatide once weekly versus metformin, pioglitazone, and sitagliptin used as monotherapy in drug-naive patients with type 2 diabetes (DURATION-4): a 26-week double-blind study. Diabetes Care. 2012;35(2):252-8.

49. Nauck MA, Meininger G, Sheng D, Terranella L, Stein PP. Efficacy and safety of the dipeptidyl peptidase-4 inhibitor, sitagliptin, compared with the sulfonylurea, glipizide, in patients with type 2 diabetes inadequately controlled on metformin alone: a randomized, double-blind, non-inferiority trial. Diabetes Obes Metab. 2007;9(2):194-205.

50. Arechavaleta R, Seck T, Chen Y, et al. Efficacy and safety of treatment with sitagliptin or glimepiride in patients with type 2 diabetes inadequately controlled on metformin monotherapy: a randomized, doubleblind, noninferiority trial. Diabetes Obes Metab. 2011:13(2):160-8.

51. Bergenstal RM, Wysham C, Macconell $L$, et al. Efficacy and safety of exenatide once weekly versus sitagliptin or pioglitazone as an adjunct to metformin for treatment of type 2 diabetes (DURATION-2): a randomised trial. Lancet. 2010;376(9739):431-9.

52. Forst $\mathrm{T}$, Uhlig-Laske $B$, Ring A, et al. Linagliptin (BI 1356), a potent and selective DPP-4 inhibitor, is safe and efficacious in combination with metformin in patients with inadequately controlled Type 2 diabetes. Diabet Med. 2010;27(12):1409-19.

53. Gallwitz B, Rosenstock J, Rauch T, et al. 2-year efficacy and safety of linagliptin compared with glimepiride in patients with type 2 diabetes inadequately controlled on metformin: a randomised, double-blind, noninferiority trial. Lancet (North American Edition). 2012;380(9840):475-83.

54. Ross SA, Rafeiro E, Meinicke T. Efficacy and safety of linagliptin $2.5 \mathrm{mg}$ twice daily versus $5 \mathrm{mg}$ once daily in patients with type 2 diabetes inadequately controlled on metformin: a randomised, double-blind, placebocontrolled trial. Curr Med Res Opin. 2012;28(9):1465-74.

55. Aaboe K, Knop FK, Visbøll T, et al. Twelve weeks treatment with the DPP-4 inhibitor, sitagliptin, prevents degradation of peptide YY and improves glucose and non-glucose induced insulin secretion in patients with type 2 diabetes mellitus. Diabetes Obes Metab. 2010;12(4):323-33.

56. Derosa G, Carbone A, Franzetti I, et al. Effects of a combination of sitagliptin plus metformin vs metformin monotherapy on glycemic control, b-cell function and insulin resistance in type 2 diabetic patients. Diabetes Res Clin Pract. 2012;98(1):51-60

57. Hermansen K, Kipnes M, Luo E, Fanurik D, Khatami H, Stein P. Efficacy and safety of the dipeptidyl peptidase-4 inhibitor, sitagliptin, in patients with type 2 diabetes mellitus inadequately controlled on glimepiride alone or on glimepiride and metformin. Diabetes Obes Metab. 2007;9(5):733-45.

\section{Submit your next manuscript to BioMed Central and we will help you at every step:}

- We accept pre-submission inquiries

- Our selector tool helps you to find the most relevant journal

- We provide round the clock customer support

- Convenient online submission

- Thorough peer review

- Inclusion in PubMed and all major indexing services

- Maximum visibility for your research

Submit your manuscript at www.biomedcentral.com/submit 